DigitALCOMMONS @WAYNESTATE-

\section{Michigan Journal of Counseling: Research, Theory and Practice}

Volume 36 | Issue 1

Article 4

3-1-2009

\title{
No Child Overlooked: Mental Health Triage in the Schools
}

\author{
F. Robert Wilson \\ University of Cincinnati, f.robert.wilson@uc.edu \\ Mei Tang \\ University of Cincinnati \\ Kelly Schiller \\ University of Cincinnati \\ Kerry Sebera \\ University of Cincinnati
}

Follow this and additional works at: https://digitalcommons.wayne.edu/mijoc

\section{Recommended Citation}

Wilson, F. R., Tang, M., Schiller, K., \& Sebera, K. (2009). No Child Overlooked: Mental Health Triage in the Schools, Michigan Journal of Counseling, 36(1), 24-35. doi:10.22237/mijoc/1235865780

This Article is brought to you for free and open access by the Open Access Journals at DigitalCommons@WayneState. It has been accepted for inclusion in Michigan Journal of Counseling: Research, Theory and Practice by an authorized editor of DigitalCommons@WayneState. 


\section{No Child Overlooked: Mental Health Triage in the Schools}

\section{F. Robert Wilson, Ph.D. Mei Tang, Ph.D. Kelly Schiller, M.A. Kerry Sebera, Ph.D. University of Cincinnati}

\section{Contact the authors at:}

Dr. F. Robert Wilson is a professor of counseling at the University of Cincinnati in the Counselor Education department. Correspondence concerning this article may be addressed to $\mathrm{Dr}$. F. Robert Wilson via email to: f.robert.wilson@ uc.edu

Mental health problems among children in schools are on the increase. To exercise due diligence in their responsibility to monitor and promote mental health among our nation's children, school counselors may learn from triage systems employed in hospitals, clinics, and mental health centers. The School Counselor's Triage Model provides school counselors with an easy-to-use, time efficient assessment tool to enable them to screen large groups of students to determine their mental health needs. By engaging in systematic mental health screening, school counselors can efficiently and effectively demonstrate their commitment to a core value of school counseling: addressing every child's social-emotional needs.

Key Words: triage, screening assessment, counselor commitment he acuity of mental health needs is increasing at an alarming rate. It has been reported that "one in five children or adolescents in the U.S. manifest a diagnosable mental health or addictive disorder" (Couse \& Srebnik, 2003). Today's children face new forms of the traditional critical stressors: grinding poverty, environmental impoverishment, economic instability, family dysfunction, increased threat of violence, temptation, and predation. According to the National Institute of Mental Health (2003), about $21 \%$ of all children between the ages of 9 and 17 are affected by some form of mental health problem. The most prevalent mental health disorders suffered by these children are anxiety disorders (13.0\%), disruptive behavior disorders $(10.3 \%)$, mood disorders $(6.2 \%)$, and substance use disorders (2.0\%). But even among the general population of school age youth, the Clarke, Coombs, and Walton (2003) survey revealed that today's children are impacted by stressors which are often precursors to mental health concerns. These concerns, listed in descending order of importance, included family problems, school examinations, school work, personal appearance, peer and intimate relationships, and bullying.

Schools serve not only as front line mental health support for children and adolescents; for many, school counselors may be the only mental health support available (Bailey, 2000; Baruch, 2001; Clarke et al., 2003; The Mental Health Foundation, 1999; Weist, Lowie, Flaherty, \& Pruitt, 2001). Limited access to mental health care is especially acute for children of poverty (Lockhart \& Keys, 1998; Morse, 2003). Responding to the emerging need for school mental health support, recent opinion advocates for organizing mental health care for young people as a school-based multidisciplinary partnership among mental health professionals (Bailey, 2000; Clarke etal., 2003; Tashman et al., 2000; The Mental Health Foundation, 1999; Weist et al., 2001). It is urged that this multidisciplinary team adopt a preventive focus (Weist, 2003), especially in school districts where resources are scarce and in which children are at greatest risk (Nabors \& Prodente, 2002). While the ASCA National Model (American School Counselor Association, 2003) specifically argues against school counselors serving as mental health therapists in the schools, it solidifies the school counselor's role in 
assessment of personal/social problems and, in a global sense, providing for student's mental health needs.

While mental health professionals, especially those in school settings, care for children and adolescents whose difficulties have triggered a referral for treatment, signs of the development of their disorder have usually been long evident (Forness, 2003). Even at a time where the field of mental health is embracing primary prevention, school mental health professionals remain tied to a tertiary care model, awaiting the eruption of disruptive symptomatology before remedial interventions are employed (Forness, 2003). To implement primary preventive measures or begin early stage remedial intervention, early identification of problems is paramount. Within-school population screening for mental health problems is a necessary precursor to the design and implementation of school-relevant, primary prevention strategies for those at risk for development of mental health concerns and can facilitate case identification for early stage mental health intervention with students who are already exhibiting the signs and symptoms of mental disorder.

Consistent with the call for increased mental health support in schools, Keys, Bemak, and Lockhart (1998) proposed that school counselors should be trained and equipped to recognize students whose behavior problems are outside the range of normal development. In response to this challenge, we will describe the core notions of mental health screening, describe a brief screening tool which can support a school counselor's assessment efforts, and, describe how the screening tools can be used in a school setting.

\section{Mental Health Screening and the Role of the School Counselor in Triage}

Despite widespread recognition of the mental health problems faced by many of today's school children and adolescents, school counselors rarely have time typically required to perform a thorough assessment of the mental health needs of their students. An assessment model called the triage model was first developed to help battlefield medical staff prioritize care according to the severity of a wounded person's injury (McMahon, 2003), provides a useful philosophy and framework for assisting school counselors to identify the overall level of mental health concerns within their school and which students are in greatest need for services.

The triage model is the key to efficient routing of medical patients to appropriate treatment. In emergency medical centers, patients with mental health concerns are first seen by a psychiatric triage nurse who conducts a rapid assessment of the patient's presenting concerns, mental health history, and current indicators of mental health problems including risk of harming self or others. Based on this rapid assessment, the triage worker then assigns an "urgency code" which is used to determine how rapidly the patient must be seen by a physician or psychiatrist and for what services (Rose \& Jagim, 2003).

The school counselor has much in common with the emergency room nurse. The school counselor's tasks are varied and are carried out in an environment where interruption is the rule rather than the exception. It would be an unusual school counselor who had the time needed to conduct a thorough mental health assessment on every student in a classroom, let alone a grade level, or the school as a whole. However, most school counselors plan time to meet each of the students, even if only briefly, to "open the door" for them and reduce their anxiety about meeting with the counselor should an educational/career or social/emotional problem arise. It is during these brief, introductory meetings with students that the triage method for mental health screening can be most valuable.

In essence, the triage model for school counselors, like its medical counterpart, calls for rapid gathering of critical screening information and rapid assignment of each student to one of three acuity categories: (a) the student does not appear to have mental health problems which require attention at this time, (b) the student has mental health problems but they are treatable with the resources available within the school, or (c) the student has mental health problems of such severity that the student cannot be properly treated within the school setting. The core of this mental health triage process is the School Mental Health Screening Interview.

\section{The School Mental Health Screening Interview}

The School Mental Health Screening Interview is a structured interview guide which can enable a school counselor to conduct a relatively comprehensive mental health screening in as little as 15 minutes. This tool includes a general information question and ten assessment domains reflecting mental health problems shown to effect the school performance of a significant portion of children and adolescents (Clarke et al., 2003; National Institute of Mental Health, 2003a, 2003b, 
2003c; Roth\& Fonagy, 1996). These assessment domains include (a) school engagement/disengagement (the extent to which the child or adolescent feels connected to the school, its culture, its rhythms, its rules), (b) lifestyle balance/imbalance (the extent to which the student has a balanced lifestyle which allows for fulfillment of a broad range of developmental needs), (c) freedom from or exposure to debilitating stressors (family problems, problems with peer and intimate relationships, problems arising from bullying and predation, problems meeting expectations for school performance), (d) mood regulation/dysregulation (depression, mania, cycling mood, suicidality, homicidality), (e) calmness/ anxiety (fears of separating from parents to come to school, generalized fearfulness, performance anxiety, fears of embarrassment or humiliation in social situations, obsessions and compulsions, and post-trauma reactions), (f) restful/disturbed sleep (insomnia, hypersomnia, failure to get restorative sleep, insufficient sleep due to over-involvement in curricular and extra-curricular activities), (d) eating regulation/dysregulation (anorexia, bulimia, subclinical eating problems, poor nutrition), (e) impulse control/dyscontrol (inattentiveness, hyperactivity, impulsiveness), (f) psychoactive substance use, abuse, or dependence, (g) physical health/illness and health maintenance/neglect (illnesses, lack of exercise, lack of access to medical attention, non-compliance with medical recommendations).

For each of these assessment areas, specific questions were crafted to help the interviewer explore problems as they are divulged. Questions were written in conversational language to minimize children's and adolescent's natural resistance to "prying" yet open the door to talking about potentially problematic areas of the child's or adolescent's life. In addition to the individual student interview form, a global recording form was developed to facilitate rapid study of data collected within a class, across a grade level, or within a school building. Finally, a shortened version was prepared for use in soliciting teacher referrals. The mental health screening interview individual record and summary data recording form and the teacher referral form are presented in Appendices A, B, and C, and are described in detail below.

\section{Implementing Mental Health Screening in the School Preparing the Counseling Staff}

For a counseling staff to initiate a schoolwide screening program, the counseling staff must be prepared. All members of the counseling staff should be in agreement about the value of screening the student population for signs and symptoms of personal, social, and emotional problems. Since some counselors may not feel comfortable with the personal nature of the questions being asked or with their sense of responsibility should an interview with a student reveal that the student is experiencing serious difficulty, a plan must be in place for referral to within-school mental health services or external referral sources.

\section{Securing Permission, Cooperation, and Support}

Before a school-wide mental health screening program can be set in place, it is critical that it has the support of the administration, teachers, and parents. Counselors wanting to establish a mental health screening program in their school are well advised to examine existing school policy and to prepare a written plan that outlines the purpose, the expected benefits, steps to be taken to minimize disruption of student learning activities, and precautions to be taken to ensure the safety and security of the students and the school. Specific plans must be in place for how the counselor and the school will respond if a student admits to being the victim of bullying by other students or neglect or abuse by parents, illegal use of psychoactive substances, or being bothered by suicidal or homicidal thoughts. Once a counselor knows a student has such serious problems, the counselor is bound by ethics to act. The counselor must be sure that the school is prepared to support the counselor in asking screening questions about these sensitive areas. On receiving support from the administration, counselors should seek to meet with the teaching faculty to win their support as well. During talks with teachers, counselors might offer teachers a referral tool (such as the one presented in Appendix C) as a way of explaining the mental health screening interview and to encourage teachers to make referrals for counseling services. Parents should be informed that counselors will be meeting individually with all students to review goals and assess their needs. This information may be disseminated through the student handbook, parent orientation meetings, and/or direct communication between the counselors and parents.

\section{Preparing the Students}

Finally, it is important that effort be made to prepare the students for the screening program. Students can be told that counselors will be meeting with every student in 
order to get acquainted and to find out how the school can be of best help to them with any problems they are having which interfere with their academic success or their personal well-being.

\section{How to Conduct the Interviews}

There are many ways a counselor might approach conducting the interviews. At one school where a mental health screening is employed, the counseling staff visited one classroom at a time. The counselor made a brief presentation to the class of students about the purpose for the interviews and the plan for conducting them. Then, students met individually with the counselor in an adjacent classroom, in a quiet place in a hallway, or in a nearby office (thereby
During the initial interview, the counselor continues work to allay student anxiety. Pointing out that all students are being interviewed so that no student is overlooked universalizes the experience. Further, the initial questions are designed to help the counselor quickly build rapport with the student. The School Mental Health Screening Record (see Appendix A) is both an interview guide and a data collection tool. When interviewing a student, the counselor can use this form as a reminder of the sorts of questions to ask. Once rapport is built, the counselor moves gently but systematically through the critical question areas, phrasing the questions in whatever way seems to resonate well with the student being interviewed. During the interview, the counselor may takebriefnotes, remembering, however, that this is a screening interview and efficiency is important. Any students who seem to be having significant personal, social, or emotional difficulties can be flagged for follow-up. significant personal, social, or emotional difficulties can be flagged for follow-up. Of course, if a student becomes significantly distressed during the interview, the counselor may decide to stop the interview, make an appointment for a longer period of time to talk, and help the student regain composure so they can return to class.

Because of its structure, the screening interview form is its own administration guide. After noting observations and anecdotal data, the counselor can code each of the mental health screening areas with a simple code to indicate whether there appears to be a problem $(+)$ : does not appear to have a problem (--) or needs reassessment (?). Next, the counselor can cutting "travel time" to and from the interviews to a minimum). With a class of 30 students, a counselor might take several days to interview everyone in the class.

During the initial interview, the counselor continues work to allay student anxiety. Pointing out that all students are being interviewed so that no student is overlooked universalizes the experience. Further, the initial questions are designed to help the counselor quickly build rapport with the student. The School Mental Health Screening Record (see Appendix A) is both an interview guide and a data collection tool. When interviewing a student, the counselor can use this form as a reminder of the sorts of questions to ask. Once rapport is built, the counselor moves gently but systematically through the critical question areas, phrasing the questions in whatever way seems to resonate well with the student being interviewed. During the interview, the counselor may take brief notes, remembering, however, that this is a screening interview and efficiency is important. Any students who seem to be having note whether it appears that a code is entered to record the counselor's level of confidence in the credibility of the information collected about this student $(\mathrm{C}$ : credible, $\mathrm{NC}$ : not credible), and a code to indicate whether the counselor believes action or intervention is needed (A: action needed; NA: no action needed). At the end of this form is space for summary comments and for recording a tally of the codes recorded. Since this is an interview record rather than a scaled instrument, there are no scores to compute. On a case-by-case basis, the data from the School Mental Health Screening Record may be used to support triage decisions: planning individual counseling interventions for those students whose problems may reasonably be treated in the school or planning for referral of those students whose problems may exceed the resources available for treatment by school personnel.

\section{Cross Sectional Summaries of Screening Interview Data}

The data from individual interviews can also be transcribed onto a cross-sectional record. The School 
Mental Health Screening Interview Summary form (see Appendix B) can be used to summarize data collected within a classroom, across a grade level, or even across all pupils in a school building. For each student, a simple code is entered under each of the eleven interview areas noting whether the student has a problem in this area $(+)$, does not appear to have a problem in this area (-), or needs reassessment to clarify the student's health status in this area (?). Next, a code is entered to record the counselor's level of confidence in the credibility of the information collected about this student ( $\mathrm{C}$ : credible, NC: not credible). Finally, a code is entered to indicate whether the counselor believes action is needed (A: action needed; NA: no action needed). When all students are entered, the counselor can tally the data by counting cases as a summary for the class, grade level, or school. This cross-sectional record can be invaluable in identifying the number and percentage of children experiencing difficulty in each of the problem areas. Critical problem areas can be targeted for both group based prevention programming for those at risk and remedial interventions for those who have become affected by the problem.

\section{Gathering Screening Data from the Teacher's Point of View}

The triage process can be significantly aided by gathering collateral information from teachers. The School Mental Health Teacher Referral Form (see Appendix C) may be used to encourage teachers to provide collateral information about their students' mental health status. Because this form is brief and logically organized, teachers can quickly and efficiently supply valuable classroom-based observations about each of the ten screening areas and indicate whether a mental health problem is suspected $(+)$, whether the student appears to be doing well (--), or whether the student's mental health status is unclear (?). A space at the bottom of the form is provided for teachers to suggest counseling services they believe might be helpful. This Teacher Referral Form could also be integrated in the Response to Intervention (RTI) process, providing data on student behaviors and identifying interventions to utilize with the students.

\section{Adapting the Screening Tool}

Counselors must be sensitive to the populations that they serve. The generic tool for conducting screening interviews (Appendix A) and its associated screening tools, the summary sheet (Appendix B), and the teacher referral form (Appendix C) can easily be adapted to suit the age range of the students being screened and the local circumstances within the school and community. For example, if one were screening grades 1 through 3 , one might reword the substance use and health status questions to be more consistent with their developmental level. Similarly, adaptations may be needed depending on the racial, cultural, and social class composition of the school. If, for example, the students to be screened come from an environment where they face known dangers (e.g., crossing dangerous streets, encountering predatory street people, chronic poverty) specific questions about those dangers and impoverishments might be added to the stressor section of the interview.

\section{A Note on Confidentiality of Screening and Referral Records}

School counselors who engage in mental health screening and triage must keep issues of confidentiality in mind. While the Family Educational Rights and Privacy Act (FERPA) gives parents and students over the age of 18 the right to inspect educational records and to control their dissemination to others, school counselors' case notes should be maintained separate from the educational record. These notes, which are to serve as memory aids for the counselor, are considered "sole possession records" and may be shielded from parental inspection. However, since the counselor may want to share the results from the School Mental Health Interview Form either in individual record format or as a cross-sectional report to other counselors, either verbally or in written format, as part of the triage process, this information may not qualify as sole possession records which may be kept confidential from parents (Cobia \& Henderson, 2007; Fischer \& Sorenson, 1996). Further, because the School Mental Health Teacher Referral Form is completed by a teacher, it cannot be considered to be protected information under the "sole possession records" provisions of FERPA. School counselors also need to establish a plan detailing secure storage for completed forms, limiting access to the forms by others, and establishing a reasonable time line for purging those records, as outlined in the ASCA Ethical Standards. 


\section{Conclusion}

School counselors have been called to respond to the changing needs of students for the past decades. Today, children and youth face unprecedented challenges - violence in schools, economic instability, and global destabilization. In response, ASCA has set national standards for comprehensive school counseling programs which call for promoting academic achievement, career development, and social/emotional well-being for all students. Early identification of mental health needs of school students and identification of those at risk for the development or exacerbation of mental health problems is the first and most important step in the prevention of more chronic and debilitating social/emotional impairment. The assessment tools introduced in this article can facilitate thorough yet efficient fulfillment of the school counselor's responsibilities.

A paramount concern for many school counselors is maximizing the value of the work they can accomplish in the minimal amount of time allotted in the school day for the counseling process. The triage screening approach permits the school counselor to cover the most frequently observed personal and environmental problem areas encountered by children and adolescents in the span of 15-20 minutes, a time frame which means less class interruption for the teacher and less instructional time missed for the student. The uncomplicated, straightforward nature of the structured assessment facilitates rapid mastery of the method by the counselor. The relatively informal phrasing of the questions seeks to build rapport with the student and encourage disclosure. Additionally, the assessment tool encourages consistency in the dialogue with students thus minimizing problems of reliability and equivalency that sometimes occur when multiple counselors attempt to screen a large group of students. Moreover, the uniformity of the assessment lends support to the counselor when the counselor's personal energy may be waning. Further, the structured straightforwardness of the assessment tools may aid in clarifying the assessment process for administrators, teachers, and staff, and demystifying the counseling process for the student body as they become more accustomed to what occurs when one meets with the counselor. Finally, it can be easily adapted to fit special needs and local conditions.

In essence, the triage screening model provides school counselors an easy-to-use, time efficient assessment tool to enable them to get acquainted with students in a timely fashion and to screen large groups of students to determine their mental health needs. With tools such as these, school counselors can address the school mental health problems now alarmingly on the increase (NIMH, 2003b; Clark, et al. 2003). By engaging in systematic mental health screening, school counselors can efficiently and effectively demonstrate their ethical commitment to a core value of school counseling: No Child Shall Be Overlooked. 


\section{References}

American School Counselor Association. (2003). The ASCA national model: A framework for school counseling programs. Alexandria, VA.

Bailey, A. (2000). A primer on school-based mental health practice: Lessons from the literature. Smith College Studies in Social Work, 70, 239-254.

Baruch, G. (2001). Mental health services in the schools: The challenge of locating a psychotherapy service for troubled adolescent pupils in mainstream. Journal of Adolescence, 24, 549-570.

Clarke, M., Coombs, C., \& Walton, L. (2003). School based early identification and intervention service for adolescents: A psychology and school nurse partnership model. Child and Adolescent Mental Health, 8(1), 34-39.

Cobia, D. C., \& Henderson, D. A. (2007). Developing an effective and accountable school counseling program (2nd ed.). NY: Pearson.

Couse, A. M., \& Srebnik, D. (2003). Before treatment: Adolescent mental health help-seeking. The Prevention Researcher, 10(4), 6-9.

Fischer, L., \& Sorenson, G. P. (1996). School law for counselors, psychologists, and social workers (3rd. ed.). White Plains, NY: Longman.

Forness, S. R. (2003). Barriers to evidence-based treatment: Developmental psychopathology and the interdisciplinary disconnect in school mental health practice. Journal of School Psychology, 41, 61-67.

Keys, S. G., Bemak, F., \& Lockhart, E. J. (1998). Transforming school counseling to serve the mental health needs of at-risk youth. Journal of Counseling and Development, 76, 381-388.

Lockhart, E. J., \& Keys, S. G. (1998). The mental health counseling role of school counselors. Professional School Counseling, 1, 3-6.

McMahon, M. M. (2003). Ed triage: Is a five-level triage system best? American Journal of Nursing, 103(3), 61-63.

Morse, W. (2003). Working with troubled youth in schools: A guide for all school staff. American Journal of Orthopsychiatry, 73, 463.

Nabors, L. A., \& Prodente. (2002). Evaluation of outcomes for adolescents receiving school-based mental health services. Children's services: Social policy, research, and practice, 5, 105-112.

National Institute of Mental Health. (2003a). Depression in children and adolescents: A fact sheet for physicians. Retrieved December 6, 2003, from http://www.nimh.nih.gov/publicat/depchildresfact.cmf

National Institute of Mental Health. (2003b). Epidemiology of mental illness. Retrieved December 6, 2003, from http:// www.surgeongeneral.gov/library/mentalhealth/chapter2/sec2_1.html

National Institute of Mental Health. (2003c). Overview of mental disorders in children. Retrieved December 6, 2003, from http://www.surgeongeneral.gov/library/mentalhealth/chapter3/sec3.html

Rose, C., \& Jagim, M. (2003). Psychiatric triage RNs in the ER: A role that promotes patient safety and reduces bedlam in the ER. American Journal of Nursing, 103(9), 101-105.

Roth, A., \& Fonagy, P. (1996). What works for whom? A critical review of psychotherapy research. New York, NY: The Guilford Press.

Tashman, N. A., Weist, M. D., Acosta, O., Bickham, L., Grady, M., Nabors, L., \& Waxman, R. (2000). Toward the integration of prevention research and expanded school mental health programs. Children's services: Social policy, research, and practice, 3, 97-115.

Weist, M. D. (2003). Challenges and opportunities in moving toward a public health approach in school mental health. Journal of School Psychology, 41, 77-82.

Weist, M. D., Lowie, J. A., Flaherty, L. T., \& Pruitt, D. (2001). Collaboration among the education, mental health, and public health systems to promote youth mental health. Psychiatric Services, 52, 1348-1351. 


\section{Appendix $A$}

Page 1 of 2

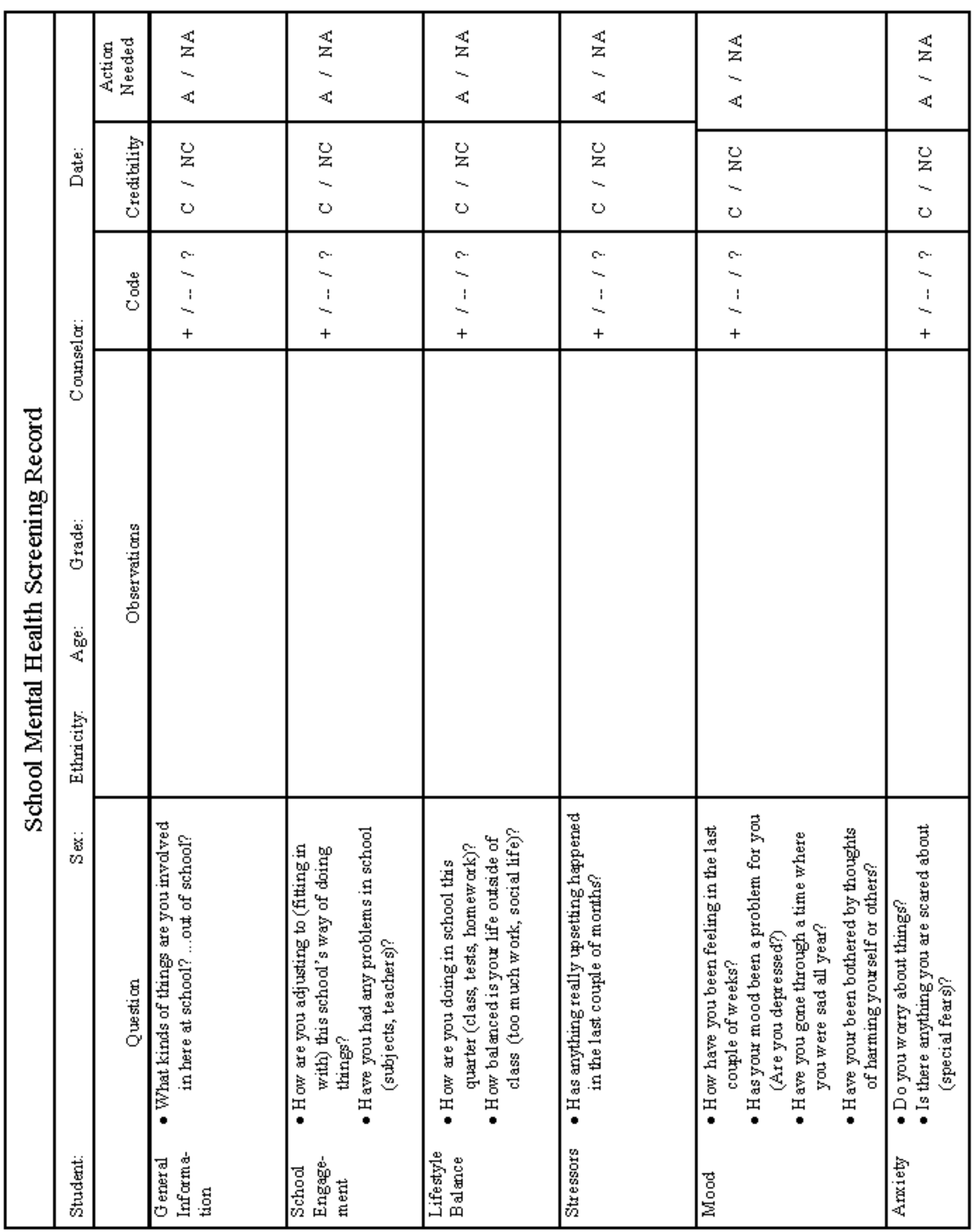




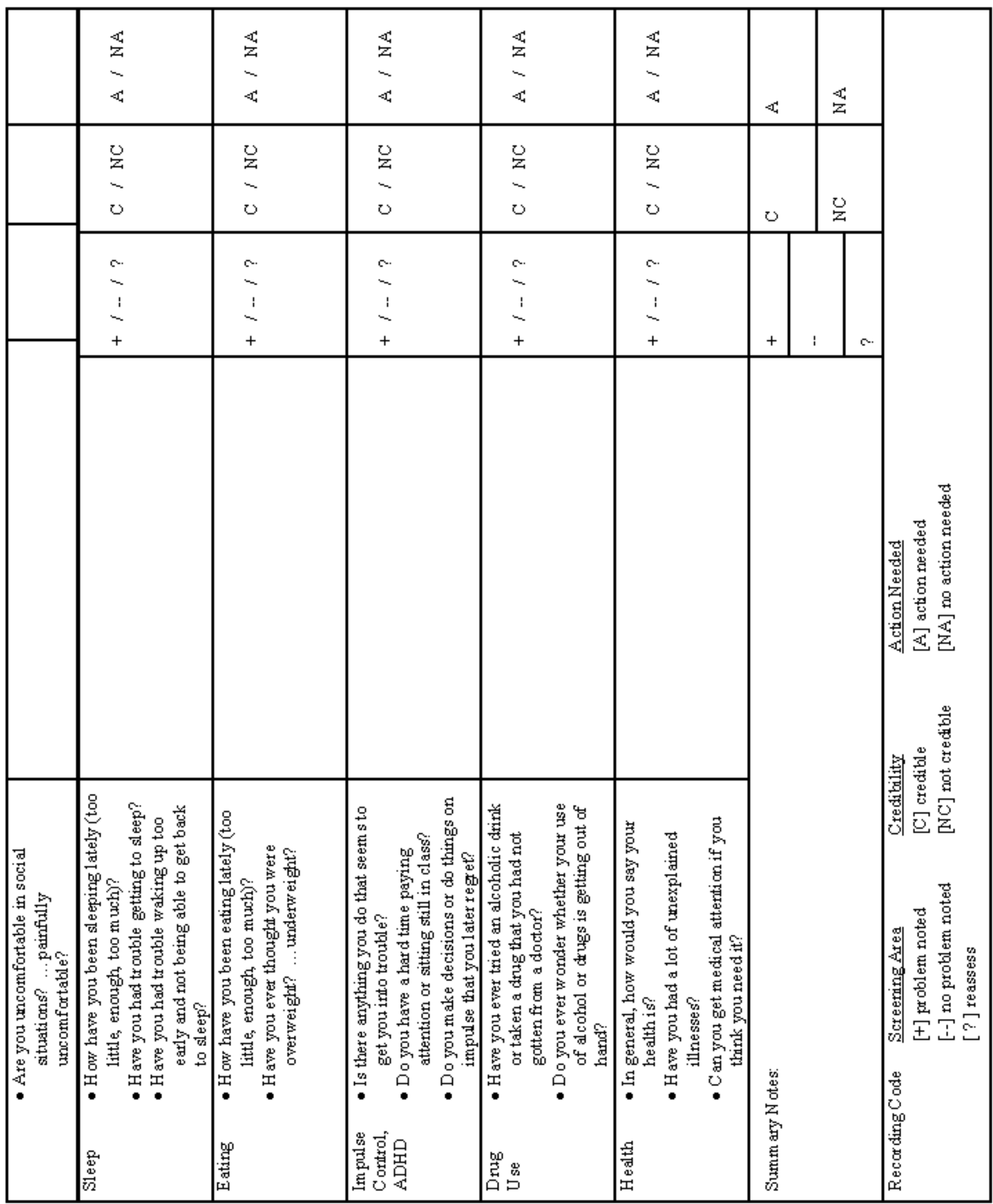




\section{Appendix B}

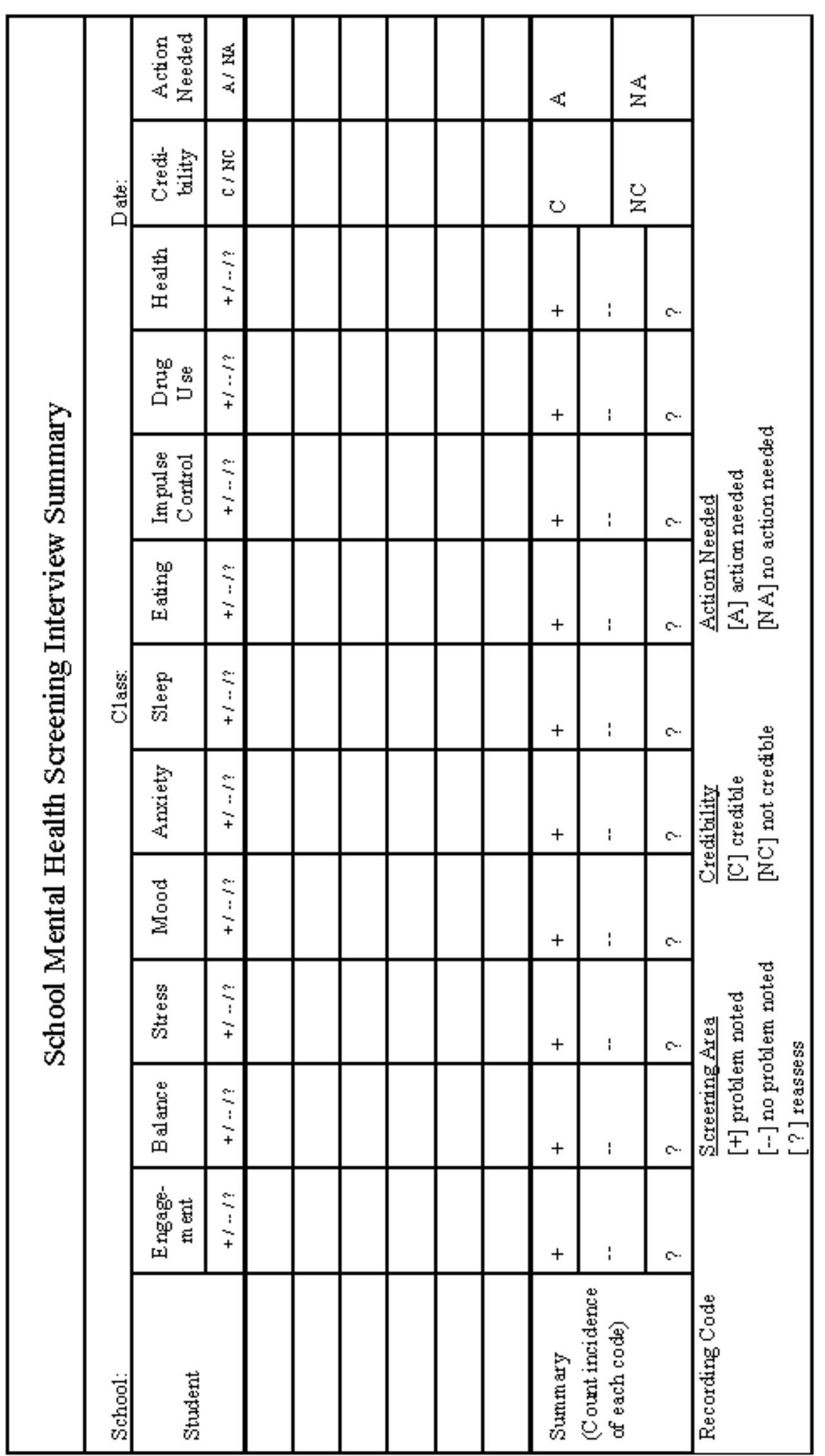




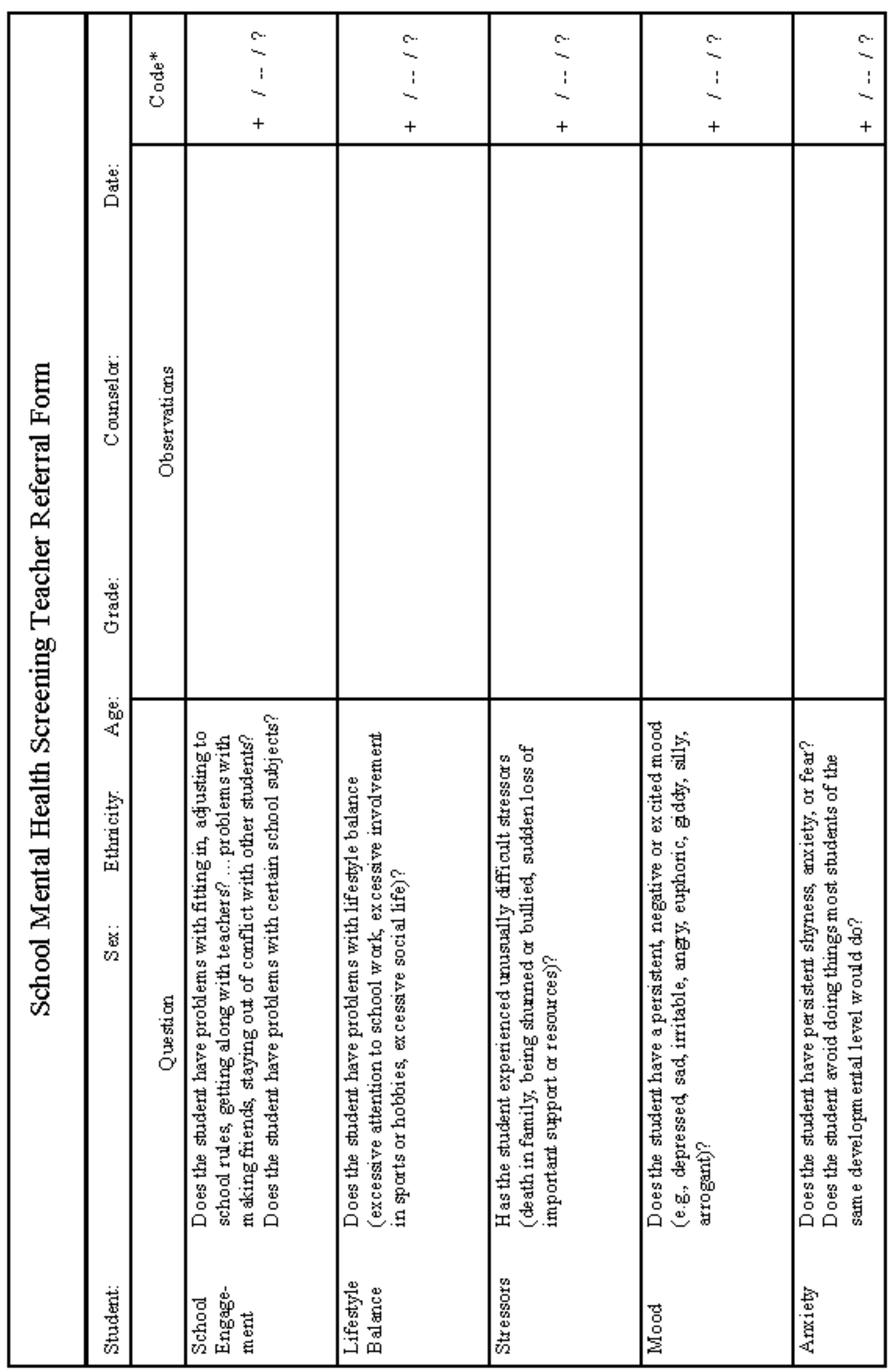




\section{Appendix C, cont.}

Page 2 of 2

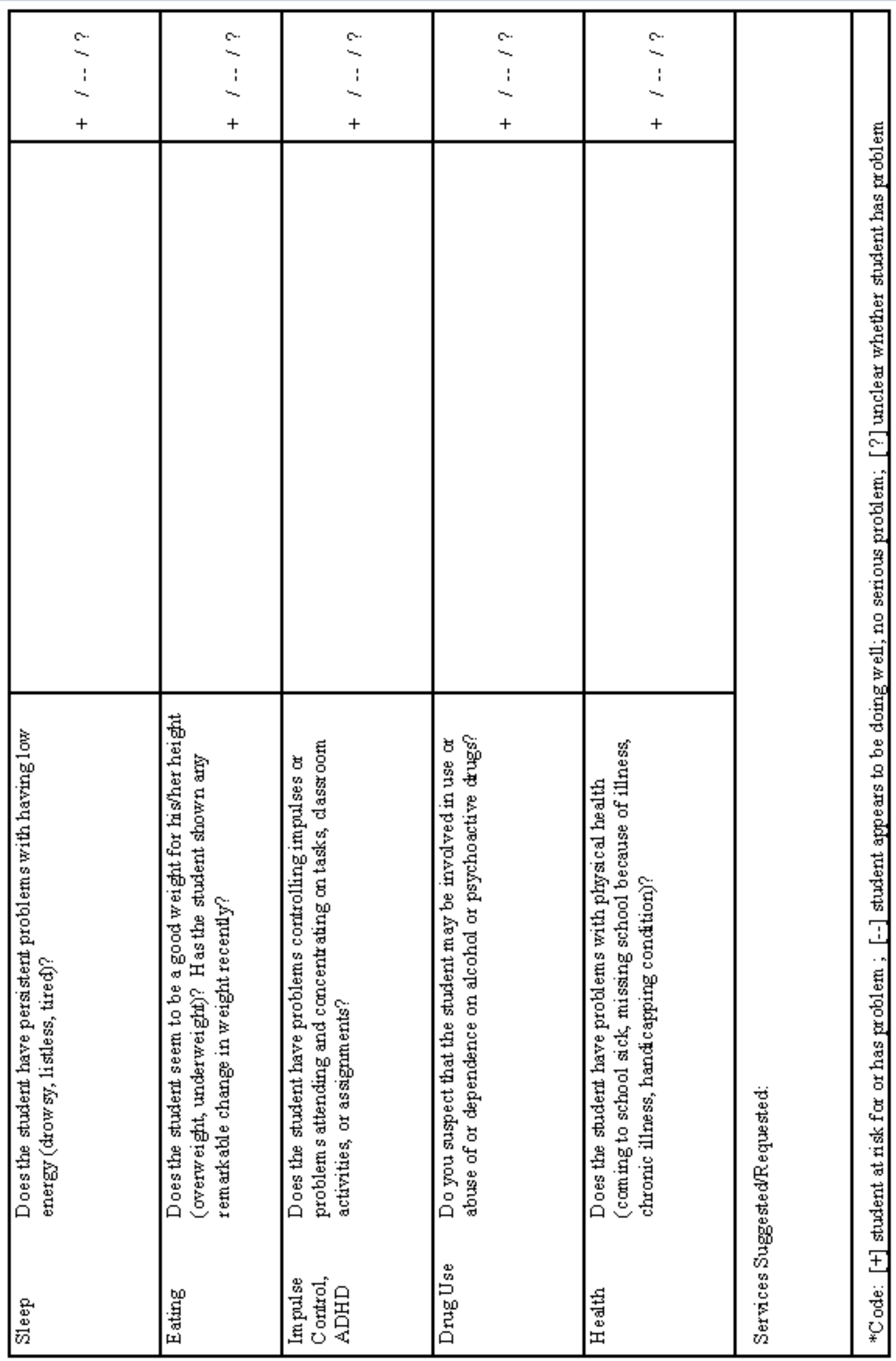

